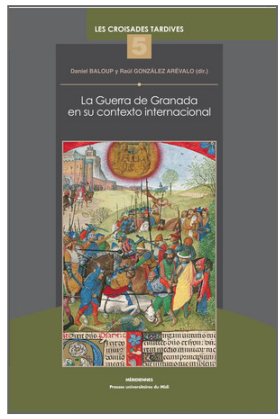

Daniel Baloup y Raúl González Arévalo (dir.)

La Guerra de Granada en su contexto internacional

Presses universitaires du Midi

\title{
Ecos contrastados de la guerra de Granada: difusión y seguimiento desigual en los contextos ibérico y mediterráneo
}

\author{
Roser Salicrú I Lluch
}

DOI: 10.4000/books.pumi. 16758

Editor: Presses universitaires du Midi

Lugar de edición: Presses universitaires du Midi

Año de edición: 2017

Publicación en OpenEdition Books: 27 febrero 2020

Colección: Méridiennes

ISBN electrónico: 9782810709694

\section{Sbooks}

http://books.openedition.org

\section{Referencia electrónica}

LLUCH, Roser Salicrú I. Ecos contrastados de la guerra de Granada: difusión y seguimiento desigual en los contextos ibérico y mediterráneo In: La Guerra de Granada en su contexto internacional [en línea]. Toulouse: Presses universitaires du Midi, 2017 (generado el 03 mars 2020). Disponible en Internet: <http://books.openedition.org/pumi/16758>. ISBN: 9782810709694 . DOI: 10.4000/books. pumi. 16758. 


\title{
Ecos contrastados de la guerra de Granada: difusión y seguimiento desigual en los contextos ibérico y mediterráneo
}

\author{
Roser SALICRÚ I LLUCH \\ Institución Milà i Fontanals (CSIC, Barcelona)
}

\section{Preludios: el fin de la guerra de Granada en el (supuesto) imaginario europeo}

En la narración de su viaje por las costas atlánticas hasta Guinea, entre 1479 y 1480, refiere el mercader flamenco Eustache de la Fosse, según leyenda de marineros, la existencia en el Atlántico de unas islas encantadas, que debían permanecer invisibles hasta que Granada fuera completa y definitivamente conquistada a los musulmanes. Pero que, según él mismo pudo comprobar durante su navegación, ya podían intuirse por el vuelo de los pájaros en una zona alejada de cualquier tierra conocida ${ }^{1}$.

Este trabajo se inscribe en el marco de los proyectos de investigación financiados «La Corona de Aragón en el Mediterráneo tardomedieval: interculturalidad, mediación, integración y transferencias culturales» (MICINN HAR2010-16361) y «Tripulaciones, armamentos, construcción naval y navegación en el Mediterráneo Medieval» (MINECO HAR2013-48433C2-1-P). Es asimismo resultante de las investigaciones del grupo de investigación consolidado por la Generalitat de Catalunya CAIMM («La Corona catalanoaragonesa, l'Islam i el món mediterrani», 2014 SGR 1559). Agradezco enormemente a Marta Manso Rubio la ayuda prestada para la localización de algunas referencias.

1 Aunque sea largo, merece la pena reproducir todo el fragmento del Viaje de Eustache de la Fosse (1479-1481), Eduardo Aznar Vallejo y Berta Pico Graña (edición, traducción y estudio), La 
Laguna, Centro de Estudios Medievales y Renacentistas de la Universidad de La Laguna (CEMYR), 2000, pp. 35-36 (pp. 18-19 para el original francés), que hace referencia a las islas: «mientras navegábamos vimos volar varios pájaros y nuestros marineros decían que esos pájaros eran de las islas encantadas, las cuales no son nada visibles debido a que un obispo de Portugal se refugió en ellas [...] cuando todas las Españas (Aragón, Granada, Portugal, Galicia, todas pertenecientes al reino de España) habían sido conquistadas por los sarracenos. Entonces ese obispo se escapó con todos los que quisieron seguirle, y fueron varios los navíos que llegaron a esas islas [...]. Y el obispo, que era un gran sabio conocedor del arte de nigromancia, encantó las islas de modo que nunca se aparecerían a nadie en tanto todas las Españas no hubieran sido devueltas a nuestra buena fe católica. A menudo los marineros veían los pájaros de la isla al navegar por ese cuadrante, sin conseguir nunca ver nada de las islas a causa del encantamiento. Ahora bien, esto es lo que sucedió estando yo negociando en el país de España: el rey y la reina de España, impulsados por la verdadera fe, tomaron la decisión de reconquistar el reino de Granada. De hecho durante mucho tiempo fueron conquistando todo el país, de modo que sólo faltaba la gran ciudad de Granada [...]. Por la época en que se mantenía el asedio delante de la ciudad de Granada estaba un navío de Portugal en el puerto de la isla de Madeira, y al verse sorprendido por una tempestad se vio obligado a hacerse a la mar, abandonando a la tripulación y al bote que habían ido a la isla. La tempestad los condujo a una isla, donde encontraron un buen puerto muy hermoso, en el que entraron para refugiarse. Después de echar el ancla, miraron hacia tierra, donde vieron a las gentes del lugar ir y venir. Pero, como habían dejado atrás el bote cuando salieron del puerto de la isla de Madeira, no pudieron hablarles ni llegar a tierra, y los de tierra tampoco vinieron a hablar con ellos. Pero estimaban que se trataba de una de las islas encantadas que empezaba a hacerse visible porque España era casi toda cristiana y el encantamiento estaba a punto de expirar, como en efecto ocurrió poco después. Y así, con buen viento el navío regresó a la isla de Madeira y contaron todo lo que habían encontrado a los de la isla de Madeira y a sus capitanes, que habían dejado allí cuando se vieron obligados a marcharse a causa de la tempestad. Y, una vez que hubieron acabado de cargar su navío, emprendieron el regreso al país de Portugal, pero cuando llegaban junto al Cabo San Vicente la tempestad fue tan fuerte que el navío se golpeó contra una roca y perecieron todos. Eso sucedió porque, al decir de algunos, cuando la isla encantada fue descubierta Granada no era totalmente cristiana, pues todavía quedaba la ciudad sin ser cristiana, y el encantamiento consistía en que duraría hasta que todas las Españas fuesen cristianas. Por ese motivo perecieron [...]. Prosiguiendo el relato de nuestro viaje, ya sabéis cómo durante el regreso a Portugal vimos volar pájaros sobre el mar, cuando no estábamos por ningún lado próximos a tierra, por lo que los marineros decían que eran los pájaros de las islas encantadas, ya que por entonces aún no se había tomado la decisión de conquistar el reino de Granada. Podíamos muy bien estar a más de 200 leguas de distancia de cualquier tierra o de cualquier isla». 
En la narración de su viaje por la península ibérica, realizado entre 1484 y 1485, y aparentemente sin ningún fundamento histórico, el silesio Nicolás de Popielovo explica que, en Andalucía, las campanas se tocaban de modo distinto que en Alemania, Francia y otros países, para recordar la pérdida de al-Andalus por parte de los cristianos. Asegura el noble viajero que solo se tañían a golpe de martillo, del mismo modo que en Alemania se tocaba a fuego. Y que no se tocarían del modo ordinario, es decir, al vuelo, hasta que Granada se reconquistase por completo a los musulmanes ${ }^{2}$.

Aunque cupiera discutir qué entendemos por europeo o si, a menudo, no confundimos el Mediterráneo europeo con Europa, tenemos asumido que, a través de los romances fronterizos, a través del teatro, a través de las novelas o a través de la literatura en general, el moro de Granada acabó convirtiéndose en un topos común, más o menos sublimado, en el imaginario colectivo ibérico y europeo posterior a la conquista de Granada; que, teñido de un romanticismo más o menos orientalizante, impregnó -o así lo hemos pretendido- tierras europeas; que su sombra se alargó, y sigue proyectándose, a través del fenómeno de la propagación turística, con ejemplos tan patentes como la actual profusión, en Granada, en cualquier idioma, de los Cuentos de la Alhambra de Washington Irving; y que ese topos idealizado continúa divulgándose, pues, todavía, de muchas maneras, en la actualidad.

Sin embargo, pese a episodios anecdóticos como el del extraño tañido de las campanas o el de las islas encantadas, que demuestran que, por lo menos en torno al inicio de la definitiva guerra de Granada, en el imaginario colectivo el sultanato estaba ya tocando verdadera y definitivamente a su fin, poco sabemos de la visión de Granada y de su guerra que se proyectó, contemporáneamente, durante la Edad Media, allende los Pirineos. Cierto es que conocemos nóminas casi interminables de decenas y decenas de caballeros europeos que, a lo largo de los siglos XIV y XV, se desplazaron hasta la península y recorrieron y visitaron sus reinos y cortes. $\mathrm{Y}$ que sabemos que, más a menudo de lo que

2 José García Mercadal, Viajes de extranjeros por España y Portugal desde los tiempos más remotos hasta comienzos del siglo XX, [Salamanca], Junta de Castilla y León, 1999 [reedición de la obra original (1952), Madrid, Aguilar], vol. I, p. 264. 
parecía, peregrinaron a Santiago pero se acercaron también a Granada, en visita cortesana o a luchar en la frontera, haciendo cristalizar de este modo, por medio de la combinación de cruzada y peregrinaje, el ideal de cruzada caballeresco en el extremo occidental europeo ${ }^{3}$.

Algunos ejemplos de esta corriente resultan emblemáticos, como la caracterización que Geoffrey Chaucer realiza, en el prólogo de sus cuentos de Canterbury, de uno de sus peregrinos, en tanto que caballero que había participado en el asedio de Algeciras, que había intervenido en expediciones al sultanato meriní de Fez y que, además, se había batido en duelo por la fe, en tres ocasiones, en Tremecén ${ }^{4}$; como el caso del poeta alemán Osvald von Wolkenstein, que poetizó su viaje a la península y su -supuesta- visita al sultanato nazarí5; como, desde luego, los viajeros procedentes de tierras imperiales Jorg Ehingen, Leo von Rosmithal o el ya señalado Nicolaus von Popplau, sin olvidar, claro está, a Hieronimus Münzer, aunque llegara a Granada poco después de su conquista cristiana ${ }^{6}$; u otros caballeros-viajeros

3 Roser Véanse Salicrú i Lluch, «Caballeros cristianos en el Occidente europeo e islámico», en Klaus Herbers, Nikolas Jaspert (eds.), «Das kommt mir spanisch vor». Eigenes und Fremdes in den deutsch-spanischen Beziehungen des späten Millelalters, Münster, Lit Verlag, 2004, pp. 217-289; Roser Salicrú i Lluch, "Galícia i Granada: pelegrinatge i exercici de cavalleria en terres ibèriques i musulmanes occidentals a la Baixa Edat Mitjana», en El cami de Sant Jaume i Catalunya. Actes del Congrés Internacional celebrat a Barcelona, Cervera i Lleida, els dies 16, 17 i 18 d'octubre de 2003, Barcelona, Publicacions de l'Abadia de Montserrat - Consejo Superior de Investigaciones Científicas, 2007, pp. 163-177; Roser Salicrú i Lluch, «Itinerarios 'cruzados': caballeros, peregrinos y viajeros bajomedievales en el Camino de Santiago», en Santiago López MartínezMorás, Marina Meléndez Cabo, Gerardo Pérez Barcala (eds.), Identidad europea e intercambios culturales en el Camino de Santiago (Siglos XI-XV), Santiago de Compostela, Universidade de Santiago de Compostela, 2013, pp. 51-66.

4 Cf. por ejemplo, entre otras ediciones o traducciones al castellano, Geoffrey Chaucer, Cuentos de Canterbury, Pedro Guardia Massó (ed. y trad.), Madrid, Cátedra, 1987, p. 66.

5 Pino Valero-Cuadra, «El viaje a Granada de un trovador alemán del siglo XV: Oswald von Wolkenstein», Sharq al-Andalus, 10-11 (1993-1994), pp. 693-710; Roser Salicrú, «Caballeros...», p. 236.

6 Para localizar sus respectivas varias ediciones, totales o parciales, véase Werner Paravicini (ed.), Europäische Reiseberichte des späten Mittelalters. Eine analytische Bibliograpbie. Teil 1. Deutsche Reiseberichte bearbeitet von Christian Halm, Fráncfort del Meno, Peter Lang, 2001; para ediciones 
como Ghillebert de Lannoy $^{7}$ o Sebastian Ilsung 8 , que nos proyectan una imagen de proverbial hospitalidad cortesana nazarí. Pero, más allá de estos «indicios circunstanciales», cabe preguntarse cuál fue la verdadera difusión internacional de la evolución del conflicto y cómo, cuándo, dónde y hasta qué punto se proyectó y se celebró, verdaderamente, más allá de las fronteras castellanas.

\section{Formas y nodos de difusión de la información}

Aunque, historiográficamente, hayan podido erigirse en nuestras mejores aliadas para el seguimiento del desarrollo del conflicto y para el enaltecimiento de la «empresa»y de los monarcas Católicos, es evidente que las crónicas castellanas no pudieron estar, todavía, al alcance de los coetáneos, es decir, no fueron ni pudieron ser transmisoras de la información y de la evolución de la guerra de Granada con la inmediatez suficiente y necesaria para su difusión y su celebración, desigual, dentro y fuera de Castilla.

Sin embargo, acaecida la conquista en el contexto de ese mundo de carta que había entrañado un exponencial incremento de la correspondencia diplomática, los Reyes Católicos sacaron provecho de y supieron utilizar debidamente, en el

en castellano, José García Mercadal, Viajes...; Jerónimo Münzer, Viaje por España y Portugal (1491-1495), Ramón Alba (ed.), Madrid, Polifemo, 1991. Véase también Roser Salicrú i Lluch, «Usi e costumi iberici agli occhi dei viaggiatori europei del Quattrocento», en Gemma Teresa Colesanti (ed.), Le usate leggiadrie. I cortei, le cerimonie, le feste e il costume nel Mediterraneo tra il XV e XVI secolo. Atti del convegno - Napoli, 14/16 dicembre 2006, Montella, Centro Francescano di Studi sul Mediterraneo, 2010, pp. 237-254.

7 Rachel Arié, «Un seigneur bourguignon en terre musulmane au XVe siècle: Ghillebert de Lannoy», Le Moyen Âge, 2 (1977), pp. 283-302; Roser Salicrú, «Caballeros...», pp. 234-235; la narración de su viaje se halla publicada en CEuvres de Ghillebert de Lannoy. Voyageur, diplomate et moraliste. Recueillies et publiées par Charles Potvin, avec des notes géographiques et une carte par JeanCharles Houzeau, Lovaina, Imprimerie de P. et J. Lefever, 1878.

8 Klaus Herbers y Robert Plötz, Caminaron a Santiago. Relatos de peregrinaciones al «fin del mundo», Santiago de Compostela, Xunta de Galicia, 1998, pp. 81-94; Roser Salicrú, «Caballeros...», p. 223.

9 Afortunada expresión metafórica acuñada por Francesco Senatore, «Uno mundo de carta»: forme e strutture della diplomazia sforzesca, Nápoles, Liguori, 1998. 
contexto ibérico pero, sobre todo, en la Europa mediterránea cristiana -aunque, en realidad, de órbita e interés preferentemente itálico y pontificio-, las eficientes redes y nodos de transmisión epistolar cancilleresco-diplomáticos, que actuaron de aparato propagandístico y tuvieron efectos reverberativos. $\mathrm{Y}$ que, además, a corto plazo, gracias a la imprenta, también tuvieron efecto multiplicador a través de la difusión literaria ${ }^{10}$.

A raíz de la difusión y explotación de la correspondencia diplomática de los embajadores u oratores de las potencias italianas, en los últimos años el conocimiento del eco y seguimiento tanto de la guerra de Granada como de las celebraciones por los éxitos castellanos en diversas ciudades italianas ha ido avanzando muy notablemente ${ }^{11}$. Pero lo que aporta sobre ellas la correspondencia diplomática de los embajadores de Florencia o de Ferrara en Nápoles puede complementarse también con las noticias archivísticas de primera mano que nos brindan tanto la cancillería ligur como la sforzesca.

10 Aunque no me vaya a ocupar, aquí, directamente, de las repercusiones narrativo-literarias, sino únicamente de las narrativo-documentales, resultan de especial interés los trabajos de María Dolores Rincón González, «La divulgación de la Toma de Granada y el Descubrimiento. Una edición de Basilea de 1494», en El reino de Granada y el Nuevo Mundo: $V$ congreso internacional de historia de América, Granada, Diputación Provincial, 1992, vol. II, pp. 2940; María Dolores Rincón González, «Presenza dell’elemento italiano nella stampa di libri spagnoli o di tematica spagnola in tipografie tedesche del XV secolo o degli inizi del XVI», en Acta conventus neo-latini bariensis. Proceedings of the Ninth International Congress of Neo-Latin Studies. Bari 29 August to 3 September 1994, Tempe, Medieval \& Renaissance Texts \& Studies, 1998, pp. 509-515; María Dolores Rincón González, «La divulgación de la Toma de Granada: objetivos, mecanismos y agentes», Anuario de Estudios Medievales, 40/2 (2010), pp. 603-615. Véase también, en este mismo volumen, la mucho más detallada aportación de Nicasio Salvador acerca de las repercusiones festivas y literarias de la conquista de Málaga en Roma.

11 Gracias, en gran medida, a los estudios de Raúl González Arévalo, «La guerra di Granada nelle fonti fiorentine», Archivio Storico Italiano, CLXIV (2006), pp. 387-418; Raúl González Arévalo, «Ecos de la toma de Granada en Italia: de nuevo sobre las cartas de Milán y Luca», en Homenaje al profesor Eloy Benito Ruano, Murcia, Sociedad Española de Estudios Medievales Universidad de Murcia, 2010, t. I, pp. 343-365; Raúl González Arévalo, «La rendición de Muhammad XII al-Zagal y la entrega de Almería en un documento de la cancillería de los Sforza de Milán (1489)», Chronica Nova, 39 (2013), pp. 335-346; véase también el trabajo que el mismo autor publica en este volumen. 
La primera, resulta claramente representativa del uso a discreción e interesado del conocimiento y difusión de la información, del juego diplomático de los tempos y de los silencios y, en definitiva, del valor atribuido y atribuible, según correspondiera, a la diplomacia formal e informal.

La segunda, por el contrario, pone de relieve la diversidad y variedad tipológica con que podía circular la información.

En torno al eco de la fase final de la guerra de Granada en Génova: tempos y silencios diplomáticos

Cuando nos centramos en la documentación propiamente diplomática, se constata la importancia atribuidan como única fuente de información contrastada y veraz, a la notificación oficial, por escrito, por parte del monarca castellano, de cualquier de sus victorias en el reino de Granada. Así, si los jurados de Zaragoza acordaron, en 1489, esperar a la llegada de la notificación real de la victoria para festejar la caída de Baza y, posteriormente, en 1492, decidieron no hacer ninguna procesión general festejando la rendición de la capital granadina hasta que no llegara a Zaragoza el despacho del rey ${ }^{12}$, en Nápoles se vivieron con preocupación las semanas transcurridas hasta que, a principios de marzo, no se recibió la carta oficial del rey Fernando el Católico sobre la toma de la ciudad de Granada, aunque la noticia hubiera ya llegado por su propio pie a la capital campana a principios de febrero ${ }^{13}$ y hubiera sido divulgada también a través de Roma y de las misivas papales. Desde luego, en determinadas coyunturas y situaciones los mutismos y el uso o no de la información al alcance eran plenamente significativos y nada inocentes.

12 Domingo J. Buesa Conde, «Manifestaciones de la religiosidad popular en la Zaragoza del siglo XV. Las procesiones devocionales, penitenciales y en acción de gracias por la toma de Granada», Aragonia Sacra, II (1987), pp. 53 y 55.

13 De acuerdo con las informaciones de los embajadores florentinos en la ciudad, la confirmación de la noticia la dio el 4 de febrero un soldado de infantería llegado a Nápoles (Raúl González Arévalo, «La guerra...», pp. 415-416; Raúl González Arévalo, «Ecos de la toma...», p. 362), aunque otras fuentes sostienen que la llegada de la información se produjo el 2 de febrero (Álvaro Fernández de Córdova Miralles, «Imagen de los Reyes Católicos en la Roma pontificia», En la España Medieval, 28 [2005], p. 305). 
Si bien la notificación oficial de la caída de Granada había llegado a Florencia por carta real castellana el 17 de febrero de $1492^{14}$, en el caso de Génova se retrasó algo más, aunque no tanto como en Nápoles. El embajador o «nuncio» que Fernando el Católico envió a la capital ligur con la misiva, el «noble Atienza» ${ }^{15}$, se personó allí a finales de mes, y sólo tras su despacho, el 29 de febrero, se notificó la buena nueva a los lugares de la Riviera Oriental y se dieron instrucciones para conmemorarl ${ }^{16}$. En cambio, el acuse de recibo de la noticia al rey «de Castilla, León, Aragón y Granada» no se expidió hasta tres días más tarde, el 3 de marzo, en primera instancia, y el 13 de marzo, en segunda ${ }^{17}$. En 1492, pues, Génova esperó a la llegada oficial o recepción formal de la nueva para reaccionar diplomáticamente ante un hecho del que, sin duda, era conocedora desde mucho antes, y no sólo por la evidente e inmediata difusión de la noticia en los círculos diplomáticos europeo-mediterráneos y papales, sino también por los destacables intereses mercantiles que, desde el siglo XIII, tenía y había mantenido radicados en el sultanato ${ }^{18}$ y que, a finales del siglo XV, tenía salvaguardados en el resto de Andalucía y, particularmente, en Sevilla. Para Génova y los genoveses, la caída de Granada en manos cristianas entrañaba la necesidad (o, dicho de otro modo, ofrecía la posibilidad)

14 Raúl González Arévalo, «La guerra...», p. 417 y nota 71.

15 Este «noble Atienza» podría ser el Joan de Atiença a quien la reina Isabel ordena pagar, por un caballo que le había comprado para obsequiar al obispo de Lombès, 21.000 maravedíes en mayo de 1481 (cf. Antonio de la Torre, Documentos sobre relaciones internacionales de los Reyes Católicos, Barcelona, CSIC, 1949-1966, vol. I, doc. 40, p. 149).

16 Archivio di Stato di Genova (en adelante, ASG), Archivio Segreto (en adelante, AS), Litterarum 34/1810, f. 79r. Génova, 29 de febrero de 1492.

17 ASG, AS, Litterarum 34/1810, ff. 80r-v y 81r-82r. Génova, 3 y 13 de marzo de 1492.

18 Sobre la presencia ligur en Granada, además de mis propios trabajos de síntesis («La Corona de Aragón y Génova en la Granada del siglo XV» y «نRepensando Granada? Presencia y penetración diferencial cristiana en el sultanato nazarí en la Baja Edad Media», reeditados en Roser Salicrú i Lluch, El sultanato nazarí de Granada, Génova y la Corona de Aragón en el siglo XV, Granada, Editorial Universidad de Granada, 2007), remito al más reciente ensayo de síntesis sobre la presencia italiana en el sultanato nazarí de Raúl González Arévalo, «Presencia diferencial italiana en el sur de la Península Ibérica en la Baja Edad Media. Estado de la cuestión y propuestas de investigación», Medievalismo. Boletín de la Sociedad Española de Estudios Medievales, 23 (2013), pp. 175-208. 
de redefinir las propias redes mercantiles y de reubicarse en el sur peninsular ibérico ${ }^{19}$.

Sin embargo, en 1487, tras la capitulación de Málaga, Génova había actuado de forma claramente distinta. La rendición malagueña se había producido el 18 de agosto de 1487 y, tres semanas después, el 7 de septiembre, el doge Paolo Fregoso ya felicitó al rey Fernando «de Castilla y Aragón» por tan meritoria victoria $^{20}$. En este caso, suponemos que la información llegó de forma no reglada y, que sepamos, no hubo notificación oficial previa a la expedición de la misiva congratulatoria ${ }^{21}$. Aun así, en ocasión de la caída de Málaga los dirigentes de la república ligur tuvieron especial interés «espontáneo» para felicitar al monarca por la victoria, seguramente para predisponerlo hacia sus mercaderes en Sevilla, en favor de los cuales le escribieron en la misma fecha acerca de un contencioso mantenido con un cierto Juan Arteaga, que al parecer se arrastraba desde hacía varios meses. No parece casual, pues, que Paolo Fregoso se tomara la molestia de escribir también, aquel mismo día, a los cónsules y mercaderes genoveses que moraban en la ciudad andaluza, explicándoles sus gestiones sobre el caso Arteaga pero teniendo cuidado de apostillar que también había escrito al rey de Castilla in gratulationem successus rerum Granate ${ }^{22}$.

Ningún otro rastro directo parece haber quedado en Génova, o por lo menos no lo he sabido encontrar, sobre la caída de Málaga ni, a lo largo de los años finales de guerra, acerca de otras victorias castellanas en Granada, hasta la llegada, en 1492, de la misión de Atienza anunciando la capitulación final del

19 También en este sentido ha trabajado y publicado, recientemente, Raúl González Arévalo, «Exilio, diversificación y superación. Estrategias de supervivencia de los Spinola de Granada ante la guerra final de conquista (1481-1492)», Reti Medievali Rivista, 14/2 (2013); Raúl González Arévalo, «Un molino en Deifontes (Granada). De Yuça de Mora a Ambrosio Espíndola (1494)», Revista del Centro de Estudios Históricos de Granada y su Reino, 26 (2014), pp. 459-472; o Raúl González Arévalo, «De las postrimerías nazaríes a los albores castellanos. Ambrogio Spinola y la continuidad de los genoveses del Reino de Granada (1478-1508)», Archivo Storico Italiano, 644 (2015), pp. 239-273.

20 ASG, AS, Litterarum 32/1808, f. 107r. Génova, 7 de septiembre de 1487.

21 Si hubiera existido, la misiva genovesa habría hecho, sin duda alguna, mención de ella.

22 ASG, AS, Litterarum 32/1808, ff. 107r-v y 107r. Génova, 7 de septiembre de 1487. 
reino. Sin embargo, y aunque no haya encontrado registrada ninguna respuesta en la cancillería ligur, sí consta que el monarca ibérico expidió a Génova, a principios de diciembre de 1489, una carta real anunciando la toma de Baza ${ }^{23}$. Sabemos también, indirectamente, que a Génova llegó, con relativa celeridad, la noticia de la entrega de Almería al Rey Católico por parte de Muhammad el Zagal. Se produjo entre el 23 y 26 de diciembre de 1489, y aunque en Génova no haya encontrado, tampoco en este caso, registro directo de la recepción de la información, en Milán, bajo cuyo dominio estaba La Superba en esos momentos, se conserva la carta que el 18 de enero de 1490 el gobernador ducal de Génova, Agostino Adorno, envió a Gian Galeazzo Maria Sforza anunciándole que aquel mismo día habían sabido que el rey Hispaniarum había tomado Almería, que «solam Granatam superesse que, vel terrore belli vel obsidione, in potestate regis brevi futura speretun», y expresando el especial interés genovés en la victoria, puesto que «in regnis Hispanie magnis negociationibus impliciti sumus» ${ }^{24}$.

En cualquier caso, y en aparente diferencia de lo ocurrido tanto en Roma como en otras muchas ciudades italianas, donde no sólo la victoria final sino también otras obtenciones de plazas se festejaron tanto con solemnes procesiones y luminarias como con representaciones teatrales, en el caso de Génova únicamente podemos estar seguros de que se realizaron relativos e inducidos «festejos» en 1492. Gracias a la orden enviada a la Riviera y a las cartas posteriormente dirigidas a los Reyes Católicos y a los mercaderes genoveses negociantes en Sevilla, sabemos que se decretaron tres días de acción

23 Antonio de la Torre, Documentos..., vol. III, doc. 119, pp. 274-275. Baza, 4 de diciembre de 1489. De acuerdo con las noticias documentales aportadas por el citado autor a partir de los registros de la cancillería catalanoaragonesa, la toma de Baza se notificó, en dos cartas distintas, al rey de Nápoles (en castellano/aragonés) y al rey de Bohemia, Ladislao II (en latín). De esta segunda carta se expidieron copias destinadas al marqués de Monferrato, a los duques de Baviera, Venecia y Saboya, al arzobispo de Zara, a la duquesa de Milán, a los duques de Borgoña y Ferrara, a Florencia y a Génova, a la duquesa de Baviera, a la reina de Hungría, al marqués de Mantua, a la reina de Inglaterra, a los mercaderes burgaleses y otros súbditos de la Corona en Brujas, y al bastardo de Borgoña (ibidem, doc. 118, pp. 273-274, y doc. 119, pp. 274-276).

24 Archivio di Stato di Milano (en adelante ASM), Carteggio Sforzesco, 995. Génova, 18 de enero de 1490. 
de gracias, con luminarias y tañido de campanas, y que fueron de obligado cumplimiento en todos los lugares de esa costa oriental ${ }^{25}$. Fue sólo después de transcurridos esos tres días de signa letitie en todo el dominio genovés, el 3 de marzo, que el doge acabó escribiendo al rey Fernando para felicitarle por la victoria, para ponerle de manifiesto su propio regocijo, para dejarle bien patente que la toma de Granada se había conmemorado durante tres días y, especialmente, que el embajador Atienza lo había presenciado en persona, tal como él mismo podría contar y certificar ${ }^{26}$.

La voluntad de agasajar al rey Católico resulta tan evidente como la de poner de manifiesto que en Génova la victoria se festejó durante tres días en presencia del embajador castellano, puesto que se insiste en ello no sólo en esta primera carta al rey Fernando sino también en la que posteriormente se mandó a ambos Reyes Católicos. La finalidad parece clara: más allá de cualquier retórica, esta segunda carta culmina con una petición de recomendación en favor de todos los mercaderes genoveses y de la posibilidad de que, en adelante, sus naves pudieran tener libre acceso al litoral granadino ${ }^{27}$. Y se remacha todavía más el clavo escribiendo a los mercaderes genoveses en Sevilla para informarles de la recepción de la embajada de Atienza comunicando oficialmente la victoria sobre Granada; destacando que el nuncio castellano había sido obsequiado con 70 ducados (40 en moneda y 30 en paños de seda por ese valor); que había podido ser testigo de las solemnidades religiosas, de los fuegos y del toque de campanas; y que se había escrito a los reyes de Castilla en congratulación de la victoria y en favor de su actividad mercantil ${ }^{28}$.

25 ASG, AS, Litterarum 34/1810, f. 79r. Génova, 29 de febrero de 1492.

26 ASG, AS, Litterarum 34/1810, ff. 80r-v. Génova, 3 de marzo de 1492.

27 ASG, AS, Litterarum 34/1810, ff. 81r-82r. Génova, 13 de marzo de 1492.

28 ASG, AS, Litterarum 34/1810, ff. 82r. Génova, 13 de marzo de 1492. Álvaro Fernández de Córdova Miralles, «Imagen...», p. 300, refiere una «embajada de felicitación [genovesa] -compuesta por Francesco Marchesi y Giovanni Antonio Grimaldi- que encontró a los reyes en Barcelona el 10 de abril de 1493», remitiendo Antonio a Rumeu de Armas, «Colón en Barcelona. Las bulas de Alejandro VI y los problemas de la llamada exclusión aragonesa», Anuario de Estudios Americanos, 1 (1944), p. 471, quien a su vez refiere el Dietari del consell barcelonés y la mención a una carta de los embajadores genoveses a los Reyes Católicos 


\section{De la información a la notificación oficial}

La concreción de la difusión del eco de la guerra de Granada debe, pues, intentar distinguir entre la llegada de la información y (la posible) notificación oficial; su (posible) respectiva significación, interpretación y, por lo tanto, transcendencia; $y$, consiguientemente, la (posible) diferenciación de reacciones y conmemoraciones desiguales.

La importancia de la notificación oficial, por escrito o por medio de embajada, queda patente, según hemos visto, tanto en tierras ibéricas como en tierras itálicas. Resulta independiente del desajuste temporal que haya podido transcurrir con respecto a la victoria. E implica, necesariamente, una reacción del destinatario, cuando menos diplomática, porque hay que contestarla por escrito, aunque también pueda llegar a pedir, directamente, que se realice algún tipo de celebración. A Girona, por ejemplo, la noticia de la conquista de Granada llegó oficialmente por triplicado. El 20 de enero de 1492, gracias a una carta enviada por los consellers de Barcelona, que lo habían sabido el 16; el 21 de enero, por carta del propio monarca; y el 22, por carta del lugarteniente general, el infante Enrique. Sin embargo, la información se conocía ya, por lo menos, desde el 17 de enero ${ }^{29}$. La carta de Barcelona y la misiva real se limitaron a notificar la caída de la capital granadina. Pero la del infante lugarteniente, en

estando en Barcelona en 1492 (sic), recogida en el Libro de las Profecías de Cristóbal Colón (cf. Juan Fernández Valverde [ed.], Madrid, Alianza Editorial, 1992, p. 113). Sin embargo, el Manual de novells ardits vulgarment apellat dietari del antich consell barceloní, Barcelona, Imprempta de Henrich y Companyía, vol. III, 1894, p. 103, señala simplemente la llegada a Barcelona de una embajada genovesa, protagonizada por el jurista Francisco Marques y el gentilhombre Joan Anthoni Grimaldo. No sé si una embajada llegada a Barcelona un año y tres meses después de la conquista de Granada debe considerarse todavía una «embajada de felicitación»... En cualquier caso, el objetivo de la embajada era la negociación de una paz con Génova (cf. por ejemplo noticias de ambos embajadores como «ciues et oratores januenses ab ipsa comuna Janue, pro tractatu eiusdem pacis ad nos destinatos» en Antonio de la Torre, Documentos..., vol. IV, doc. 222, pp. 267-268).

29 Véase Luis Batlle y Prats, «Fiestas en Gerona por la conquista de Granada, enero-febrero de 1492», Anales del Instituto de Estudios Gerundenses, I (1945), pp. 94-107. En adelante, salvo indicación contraria, las referencias a Girona proceden de este trabajo. 
cambio, ordenaba la celebración de festejos. Por sus especificidades geográficas, en el caso de Mallorca a menudo la documentación incluso detalla la vía de llegada oficiosa de las noticias, que suele ser a través de Ibiza o de Alicante. Y suele insistirse, a posteriori, en la necesidad de verificar o de confirmar dichas informaciones ${ }^{30}$.

Ocasionalmente, y a más pequeña escala, la difusión de la caída de Granada o de otras plazas nos ilustra claramente sobre las vías más habituales de transmisión de la información: de la misma manera que Génova la anunció a todas las poblaciones de su Riviera, la ciudad de Mallorca reverberó de inmediato la noticia hacia el resto de lugares de la isla, y Girona expidió copia de la carta real recibida por lo menos a Sant Feliu de Guíxols, Besalú y Torroella de Montgrí. Otras veces, por el contrario, lo que queda patente es el interés de algunas villas de importancia secundaria por conocer mayores detalles sobre el desarrollo de la actividad bélica. Sería el caso de Cervera, que en enero de 1492 habría pedido nuevas a Barcelona ${ }^{31}$. O, en febrero de 1490, al poco de la rendición de Almería, de Mallorca, que veía tan cercano el fin del Islam granadino que incluso preguntó a la capital catalana qué tipo de festejos preveía organizar para celebrarlo.

Lo que sí, acaso, puede sorprender, es la desigual difusión de la información entre los distintos lugares, hecho que condicionaba también la posible consiguiente celebración de la caída de determinadas plazas.

30 Maria Barceló Crespí, «El eco de la guerra de Granada en Mallorca (1483-1492)», en La Peninsula Ibérica en la Era de los Descubrimientos (1391-1492). Actas III Jornadas Hispano-Portuguesas de Historia Medieval, Sevilla, Junta de Andalucía, 1997, vol. II, pp. 1373-1386. En adelante, salvo indicación contraria, las referencias a Mallorca proceden de este trabajo, aunque también sea de consulta obligada el posterior Maria Barceló Crespí, Els Llitrà. Una nissaga de notaris a la Mallorca baixmedieval, Mallorca, Lleonard Muntaner, 2001.

31 Jaume Vicens Vives, Ferran II $i$ la ciutat de Barcelona, Barcelona, Vicens Vives, 2010, vol. II, p. 171. Vicens también refiere, ibidem, nota 303, otras comunicaciones de Barcelona a villas de su término «que se lo pedían». 
Aunque, a menudo, en los archivos locales no haya quedado rastro escrito de la llegada de la información ${ }^{32}$, sí que, en cambio, puede haberlo de los festejos que constituyen prueba de ello. En la Corona de Aragón, en Cervera, por ejemplo, consta únicamente la celebración de (¿e, indirectamente, la llegada de la información sobre?) la obtención de Málaga (1487) ${ }^{33}$, Baza (1489) ${ }^{34}$, Almería (1489) $)^{35}$ y Granada ${ }^{36}$. En Zaragoza, a las conmemoraciones por estas plazas se les puede sumar la de Guadix (1489) ${ }^{37}$. Habiendo recibido, antes, cartas del monarca anunciándolo ${ }^{38}$, Barcelona felicita además a Fernando por la obtención de Loja, Illora y Moclín (1486) ${ }^{39}$. Consta, igualmente, que en Barcelona se recibieron cartas reales informando, por lo menos, de la toma de Alhama ${ }^{40}$, del atentado perpetrado el 20 de junio de 1487 en el real del asedio de Málaga ${ }^{41}$, de la toma de Málaga ${ }^{42}$, de la entrega de Almería ${ }^{43}$ y de la rendición

32 O quizás, mejor dicho, no sabemos si ha quedado rastro, puesto que de muchos de ellos no se ha realizado todavía un vaciado sistemático... pese a que la evidente calidad de información que brindan algunas de las notificaciones es la mejor prueba de que convendría llevarlo a cabo.

33 Arxiu Comarcal de la Segarra (en adelante ACSG), Cervera, Fons Municipal (en adelante FM), Crides, 1487, f. 44v. Cervera, 15 de septiembre de 1487. Debo todos los datos documentales referidos a Cervera a la gentileza de mi colega Pere Verdés Pijuan.

34 ACSG, Cervera, FM, Consells, 1489, f. 1v. Cervera, 30 de abril de 1489.

35 ACSG, Cervera, FM, Consells, 1490, f. 11r. Cervera, 20 de enero de 1490.

36 ACSG, Cervera, FM, Ordinacions, 1492, ff. 57r-58v. Cervera, 27 de enero de 1492.

37 Domingo J. Buesa Conde, «Manifestaciones...», p. 54.

38 La carta real que notificaba la toma de Loja el 29 de mayo de 1486 llegó a Barcelona el 19 de junio (Manual de novells ardits..., vol. III, p. 53).

39 Jaume Vicens Vives, Ferran II..., vol. I, p. 401.

40 La carta llegó a la ciudad condal el 20 de marzo de 1482, anunciando la entrada a la ciudad del marqués de Cádiz y de otros capitanes con 5.000 lanzas y 6.000 peones. Se festejó con un Te Deum en la catedral barcelonesa (Manual de novells ardits..., vol. III, pp. 23-24).

41 Ibidem, pp. 59-61, en una extensa glosa de la carta real, que parece ser muy cercana de la que dio a conocer parcialmente López de Coca (José Enrique López de Coca Castañer, Historia de un magnicidio frustrado, Málaga, Servicio de Publicaciones de la Universidad de Málaga, 2008, pp. 18-19; agradezco al autor que, tan amablemente, me facilitara el acceso a dicha publicación): el Manual de novells ardits aporta muchos detalles sobre el incidente y, entre otras cosas, certifica la controvertida presencia de la reina Isabel en el real malagueño en el momento del atentado. 
de Granada. Y que se recibió certificación de la caída de Baza44. La carta de Fernando el Católico informando Barcelona de la conquista de Granada llegó a la ciudad el 18 de enero de 1492. Pero, puesto que anteriormente muchos particulares ya habían informado de la noticia, justamente el día antes, el 17 de enero, el Concejo de Ciento había ya decidido hacer grans olimares (sic) ${ }^{45}$.

Como nodo de comunicaciones marítimas de importancia capital en el Mediterráneo occidental medieval, Mallorca recibió noticia y festejó muchos más acontecimientos que los ya indicados anteriormente en otros lugares: la captura de Boabdil (1483), la caída de Cohín, Cártama, Ronda y Casarabonela (1485), la conquista de Loja (1486), la de Vélez-Málaga (1487), y la de Guadix y Almuñécar (1489). Valencia solemnizó, entre otros hechos ${ }^{46}$, la prisión de Boabdil, la toma de Álora (1484) y las conquistas de Málaga, Baza y Granada, aunque lo sabemos solo indirectamente, a través de los gastos municipales destinados al pago de las celebraciones, y no por la correspondencia diplomática municipal -porque, al igual que en Barcelona, en Valencia está

42 La carta, anunciando la sumisión de Málaga el 18 de agosto de 1487, llegó a Barcelona el 7 de septiembre. Aquel día y los dos siguientes se hicieron alimaras en la ciudad, y el 12 de septiembre solemne procesión que siguió el recorrido de la del día de Corpus (Manual de novells ardits..., vol. III, pp. 62-63).

43 Carta real recibida el 8 de enero de 1490 sobre la entrega de la ciudad de Almería por parte del rey de Guadix el 22 de diciembre de 1489 (ibidem, p. 78).

44 En este caso, el dietario barcelonés indica que la nova certa, es decir, la noticia certera, de la rendición con ciertos pactos de la ciudad de Baza al rey Fernando, acaecida el 4 de diciembre de 1489, llegó a Barcelona el 14 de diciembre; no se refiere carta real, pero puede inducirse, en cambio, que la información sin certificar había llegado incluso antes (ibidem, p. 76). El 7 de enero de 1490 se celebró procesión general en acción de gracias por la victoria obtenida sobre Baza $e$ altres castells e viles del reino de Granada (ibidem, p. 78).

45 Ibidem, p. 92.

46 De acuerdo con Salvador Carreres Zacarés, Ensayo de una bibliografía de libros de fiestas celebradas en Valencia y su antiguo reino, Valencia, Hijo de Vives Mora, 1925, pp. 96-97 y doc. XxxIx, «se celebraron muchas fiestas con motivo de las victorias del Rey Católico en su guerra contra Granada» pero únicamente, «por no citar otras» (p. 96), refiere las tres que acabamos de indicar. Sobre la caída de Granada, véanse también algunas referencias en Rafael Narbona Vizcaíno, Memorias de la Ciudad. Ceremonias, creencias y costumbres en la historia de Valencia, Valencia, Ajuntament de València, D.L. 2003. 
pendiente la realización de un vaciado documental sistemático-. En cualquier caso, los fondos de la Generalitat valenciana conservan también, por lo menos, una interesantísima descripción, de primera mano, de los preparativos del sitio de Loja que Jaime de Santángel envió a los diputados del General del reino ${ }^{47}$.

En la península Itálica, y según hemos visto ya, Génova sólo parece hacerse eco oficial de la caída de Málaga y de la pérdida de la capital granadina, aunque recibió, supuestamente, noticia directa de la obtención de Baza y difundió en Milán la rendición de Almería. Que sepamos, a Florencia llegó únicamente noticia oficial directa de la toma de $\mathrm{Baza}^{48}$ y de la de Granada ${ }^{49}$, mientras que el resto de informaciones se difundieron a través de los embajadores florentinos en Nápoles ${ }^{50}$. En Nápoles, se recibieron por lo menos cartas o informaciones reales directas acerca de la toma de Álora ${ }^{51}$, Loja ${ }^{52}$, Baza ${ }^{53}$ y, ya lo hemos señalado, la caída Granada. Pero, puesto que en alguno de los casos las fuentes de información de que disponemos son indirectas, es posible que fueran otras

47 Archivo del Reino de Valencia (ARM), Generalitat, 1947, ff. 46r-47r, documento que he podido conocer gracias a Ernest Belenguer Cebrià, València en la crisi del segle XV, Barcelona, Edicions 62, 1976, p. 98, y Ernest Belenguer Cebrià, Fernando el Católico y la ciudad de V alencia, Valencia, Publicacions de la Universitat de València, 2012, p. 114. Tengo en preparación su edición y estudio. Se trata de una carta registrada entre la documentación archivística valenciana que tenía por objeto ampliar las informaciones más escuetas de los acontecimientos que Santángel sabía que ya habían llegado previamente a los diputados del General de Valencia a través de una real misiva. Santángel escribe desde Écija, donde estaba con el rey y, a mi entender, creo que está claro que copia su relato, redactado en catalán, de algún modelo puesto en circulación por el propio entorno cortesano. Porque, de otro modo, resulta poco convincente que el autor de la misiva pueda recordar de memoria el nombre de todos los nobles que acompañaron al rey Fernando, o tantos detalles sobre lugares, maniobras, número de habitantes y efectivos militares, demasiado concretos como para pensar en un relato espontáneo. Como señalaré luego, esta carta nos remite ineludiblemente al tipo de modelo y contenido de las cartas conservadas en Milán sobre el asedio de Málaga, la rendición de Almería o la caída de Granada (vide infra).

48 Véase la nota 24.

49 Cf. Raúl González Arévalo, «La guerra di Granada...», pp. 417-418.

50 Ibidem, «La guerra di Granada...», passim.

51 Antonio de la Torre, Documentos..., vol. II, doc. 124, pp. 110-111.

52 Junto con Illora, Moclín y Colomera, ibidem, docs. 47 y 48, pp. 306-309 y 310-312.

53 Antonio de la Torre, Documentos..., vol. III, doc. 118, pp. 273-274. 
muchas $^{54}$. Tras la caída de Granada, por lo menos, Fernando II también escribió directamente a Venecia, que, en este caso, respondió enviando incluso una legación para congratularse con los Reyes Católicos ${ }^{55}$. Y, en 1488, había notificado tanto al papa como al maestre de Rodas la toma de Vera y de otros lugares cercanos ${ }^{56}$. No entraré en detalles sobre el caso, especial, de Roma, a cuyas particularidades se han referido y tienen previsto referirse, en breve, otros autores $^{57}$. Pero sí conviene destacar, en cambio, la documentación milanesa, que resulta tan diversa como sorprendente y gratificante.

54 Las noticias llegadas a Nápoles han sido estudiadas a través de la correspondencia de los embajadores florentinos en Nápoles, y expresiones como «Sonci lettere di Spagna et contano che» (Raúl González Arévalo, «La guerra di Granada...», p. 396) pueden responder tanto a la llegada de noticias directas, oficiales o no, como a la llegada de informaciones de segunda mano. De todos modos, también hay que tener en cuenta que una cosa es la notificación oficial y específica de la toma de alguna plaza concreta, como sería el caso de Baza (cf. nota 23), y otra la inclusión de referencias al desarrollo de la contienda en la correspondencia real, como sería el caso de Loja; las dos cartas señaladas en la nota 52 (dirigida una al rey y otra a la reina de Nápoles), memoriales de embajada que informan sobre la caída de Loja e Illora y del asedio de Moclín, añaden al día siguiente, en un post expedite final, la rendición de Moclín y la entrega de Colomera.

55 Álvaro Fernández de Córdova Miralles, «Imagen...», p. 300 y nota 187; remite a María del Carmen Pescador del Hoyo, «Dos cartas inéditas al Dux de Venecia sobre la toma de Granada», Estudios de Edad Media de la Corona de Aragón, VI, 1956, pp. 477-483, para la carta enviada a Venecia; y a Antonio de la Torre, Los Reyes Católicos y Granada, Madrid, Instituto Jerónimo Zurita - CSIC, 1946, p. 134, para la respuesta de los monarcas castellanos agradeciendo el envío de la embajada (publicada también en Antonio de la Torre, Documentos..., vol. IV, p. 33, doc. 45).

56 Antonio de la Torre, Documentos..., vol. III, p. 118 y 147-148, docs. 132 y 157.

57 Desde los trabajos más recientes ya citados de Álvaro Fernández de Córdova Miralles, «Imagen...», y Nicasio Salvador, en su contribución a este mismo volumen, sobre la conquista de Málaga, hasta la monografía que este último tiene en preparación sobre las repercusiones festivas y literarias de la guerra en la capital pontificia, pero sin olvidar otras contribuciones más antiguas, como por ejemplo Fabrizio Cruciani, «Feste per la conquista di Granata», en Fabrizio Cruciani (ed.), Teatro nel Rinascimento, Roma 1450-1550, Roma, Bulzoni, 1983, pp. 228-239. Tómese en cuenta, sin embargo, que para el caso de Roma se han estudiado fundamentalmente fuentes literarias y narrativas, no fuentes documentales. 
En torno al eco de la guerra de Granada en las fuentes milanesas: entre la información de primera mano y los sumarios divulgativos

En Milán se conservan, por lo menos, informaciones - de tipo bien distintosobre la conquista de Alhama, sobre el cerco de Málaga, sobre la caída de Almería y la prisión del Zagal, y sobre la entrega de Granada. En el caso de Alhama, se trata de una carta en castellano (que se diría, en principio, que es una copia) del rey Fernando el Católico a algún monarca-¿quizás el rey de Nápoles? -, fechada en Medina del Campo el 12 de marzo de 1482. Anuncia y refiere, de forma relativamente detallada, la toma de la ciudad el «jueves çaguero día del mes de febrero más circa passado» ${ }^{58}$, confirmando documentalmente, pues, la fecha que señalan la mayor parte de los cronistas castellanos ${ }^{59}$. Sobre Málaga contamos, en Milán, con una carta parcialmente exhumada por López de Coca, carta en castellano que fue enviada desde el campamento cristiano a la corte milanesa y que parece conservarse acompañada de una traducción al italiano. La carta refiere algunos datos, aparentemente inéditos, relacionados con el intento frustrado de asesinar a los Reyes Católicos perpetrado por un sufí tunecino durante el cerco de la ciudad $(1487)^{60}$. Aunque, como he indicado previamente ${ }^{61}$, el relato milanés parece ser altamente parecido al relato de los hechos que llegó a Barcelona sobre ese mismo ataque, y que, hasta la fecha, había pasado desapercibido a los historiadores, pese a estar recogido y publicado, con todo lujo de detalles, en el dietario del concejo de Barcelona ${ }^{62}$.

En cuanto a Almería, en Milán se conservan por lo menos dos noticias hasta ahora inéditas. En primer lugar, la ya nombrada carta genovesa de 18 de enero de 1490 que atestigua, indirectamente, la celeridad con que la noticia de la toma

58 ASM, Carteggio Sforzesco, 653, 140. Medina del Campo, 12 de marzo de 1482. Tengo en preparación su edición y estudio.

59 Cf. Antonio de la Torre, Los Reyes Católicos..., pp. 26-27.

60 José Enrique López de Coca Castañer, Historia de un magnicidio..., pp. 18-19 (ASM, Carteggio Sforzesco, 656, 65).

61 Cf. nota 41.

62 Manual de novells ardits..., vol. III, pp. 59-61. 
de Almería había llegado a Génova63. En segundo lugar, una carta sin autor ni fecha precisa, aunque escrita probablemente el 14 de abril de 1490, porque así consta en una anotación marginal de la misma, dirigida a un cierto Francesco y escrita en italiano, donde se le agradece el envío, conjuntamente con otra carta suya, de «la copia de le lettere scripte per la Maiestà del Re de Spagna al magnifico Belprato ${ }^{64}$ del'havuta de Almarie, cità che era del re de Granata» ${ }^{65}$. Pero también se conserva, en Milán, una carta dirigida al gobernador y a los ancianos de Génova, del 1 de febrero de 1490, que se refiere, genéricamente y sin más precisión, a los éxitos que el «serenissimus Hispaniarum rex» había obtenido «adversus mauros» y en beneficio de la fe cristiana ${ }^{66}$. Por la fecha, podría corresponderse con la toma de Almería, y podría ser respuesta, quizás, a la carta genovesa de 18 de enero anunciando la caída de Almería. A otro nivel, más de relación informativa que de correspondencia diplomático-documental, debemos situar la conocida descripción conservada, en italiano, sobre la toma de Almería -y Baza, Purchena, Guadix...- y la rendición de Muhammad el Zagal, editada en 1864 por Barrera Pezzi y reeditada recientemente por González Arévalo ${ }^{67}$.

En cuanto a la caída de Granada, Milán conserva una carta dirigida a los Reyes Católicos, fechada a 21 de abril de 1492, que se hace eco de la rendición y que notifica el envío a Castilla, en embajada congratulatoria, del camarero de Ludovico Sforza Andrea Cossa ${ }^{68}$. Sin embargo, anticipándose a los hechos pero demostrando hasta qué punto los círculos diplomáticos -y mercantiles, tanto de órbita terrestre como marítima- estaban pendientes de la evolución de la

63 Véase, más arriba, el texto correspondiente a la nota 24.

64 ¿Simonetto Belprato, embajador de Ferrante en la corte sforzesca?

65 ASM, Carteggio Sforzesco, 993. La referencia directa a una carta relatando la toma de Almería quizás podría remitirnos (aunque se aluda a ella como carta real...) a la descripción de la misma conservada en traducción italiana (cf. el texto correspondiente a la nota 67).

66 ASM, Carteggio Sforzesco, 995.

67 ASM, Carteggio Sforzesco, 653, núm. 330. Ed. por Carlo Barrera Pezzi, Documenti inediti italoispani esistenti nei Reali Archivi di Milano raccolti e comentati da, Pinerolo, Tipografia Chiantore, 1864, doc. IV, pp. 27-28, y reed. por Raúl González Arévalo, «La rendición...», pp. 344-345. Agradezco enormemente a Raúl González Arévalo que me haya facilitado el acceso directo al tan difícilmente localizable trabajo de Barrera Pezzi.

68 ASM, Carteggio Sforzesco, 656, 105. 
situación del sur peninsular ibérico, a finales de diciembre de 1491 el embajador milanés residente en Venecia ya notificaba -indebidamente...- al Duca que, «per via de Mercadanti», se había sabido que el rey «de Hispania ha havuto Granada», información que, al parecer, procedía de Lión ${ }^{69}$. Finalmente, en Milán también se conserva otra carta o relato cronístico-informativo, en italiano, de estilo semejante al de la información sobre Almería, pero referido a la toma de Granada, cuyo encabezamiento indica que se trata de una «Copia lettere de lo archabazello collateralle seu barisello del re di Spagna al episcopo astrocinese (sic) Rome», y que narra con todo lujo de detalles la caída de la capital nazarí. La existencia de esta carta era conocida gracias a la edición de Barrera Pezzi de 1864, y había sido difundida por Pescador del $\mathrm{Hoyo}^{70}$.

Pero resulta que, además, en Milán se conserva también el original, en latín y hasta ahora inédito, de esa misma carta, que reza, en su encabezamiento, «Hoc est exemplum quorundam litterarum archabazelli collaterali seu bariscello regis Hyspaniam ad reverendissimum episcopum astrocinensem (sic) oratorem regis presenti Roma» ${ }^{71}$.

Por lo tanto, la carta milanesa en italiano que conocíamos hasta ahora a través de Barrera Pezzi no es sino una traducción literal al italiano ${ }^{72}$ de una carta, escrita en perfectísimo latín y conservada también en el archivo milanés, que a su vez sería copia de otra carta, en latín, dirigida al arzobispo de Astorga.

69 Cf. Carlo Barrera, Documenti.., p. 29, nota 1.

70 ASM, Carteggio Sforzesco, 656, 16, ed. por Carlo Barrera, Documenti..., doc. v, pp. 29-31; M del Carmen Pescador del Hoyo, «Cómo fué de verdad la toma de Granada a la luz de un documento inédito», Al-Andalus, 20/2 (1955), pp. 292-293. Puesto que Barrera Pezzi no publica el encabezamiento que acabo de transcribir en el texto, Pescador del Hoyo tomó como simple suposición del estudioso italiano el hecho de que la carta estuviera dirigida al obispo de Astorga.

71 ASM, Carteggio Sforzesco, 653, 341. Espero poder emprender, en breve, la edición y estudio de la versión latina, contrastada con su versión en italiano y con el resto de cartas semejantes conservadas.

72 Hasta tal punto literal que incluso traslada al italiano el error de transcripción de astrocinensem $>$ astrocinese (por astoricensem). 


\section{Nodos de transmisión y formas de difusión propagandística de las victorias}

El contenido del «anónimo milanés» sobre la toma de Granada, que ahora conocemos en su doble versión latina e italiana, difiere, aunque esté próximo, de las descripciones narrativo-descriptivas de la carta en castellano de Cifuentes ${ }^{73}$, de la carta -en francés- del «anónimo francés» conservado en París y en Granada ${ }^{74}$, de la carta en italiano de Bernardo del Roi a Venecia ${ }^{75}$, de la carta en latín de Alonso de Palencia al obispo de Astorga ${ }^{76}$, y de la carta que el propio el obispo de Astorga, Juan Ruiz de Medina, envió a Luca, Ferrara, Siena y Módena, conservada en italiano ${ }^{77}$. Constituye, pues, un eslabón más -a examinar con detenimiento confrontado, por lo menos, con el latín de la carta de Alonso de Palencia-, que acredita (junto con los demás ejemplos parecidos detectados para el caso de Alhama ${ }^{78}$, de Loja ${ }^{79}$, del «atentado» en el asedio de Málaga ${ }^{80}$ o de Almería ${ }^{81}$ ) la deliberada voluntad de divulgar, más allá de la propia documentación diplomática y de la circulación «espontánea» o no reglada de la información, las hazañas bélicas castellanas en el mundo cristiano occidental. Y abona la existencia (¿la creación?) de un género epistolar específico, particular, de «informes oficiales», dedicado a esparcir las victorias y la fama de los Reyes Católicos. En el que, según ya se sabía, los protonotarios

de los monarcas Bernardino López de Carvajal y Juan Ruiz de Medina (jnuestro

73 Ed. Ma del Carmen Pescador del Hoyo, «Cómo fué...».

74 Ed. Georges Hamel, «Un incunable français relatif à la prise de Grenade», Revue Hispanique, XXXVI (1916), pp. 159-169.

75 Ed. Ma del Carmen Pescador del Hoyo, «Dos cartas...».

76 Reed. en Alonso de Palencia, Guerra de Granada. Edición facsímil. Estudio preliminar por Rafael Gerardo Peinado Santaella, Granada, Editorial Universidad de Granada, 1998, Apéndice, pp. LXXV-LXXXVI -versión latina- y LXXXVI-XCVII -traducción castellana-.

77 Véase, reeditada, la versión conservada en Luca en Raúl González Arévalo, «Ecos de la toma...».

78 Véase el texto correspondiente a la nota 58.

79 Véanse la nota y el texto correspondientes a la nota 47.

80 Véase el texto correspondiente a la nota 60.

81 Véase el texto correspondiente a la nota 67. 
obispo de Astorga!), tuvieron un papel especial y muy activo, empleando Roma como nodo de propagación ${ }^{82}$.

No decimos, pues, nada totalmente nuevo. Pero está claro que, a través del caso milanés, podemos certificar que nos encontramos frente a relatos, prácticamente frente a «crónicas», de la toma de Granada, y no frente a correspondencia o a cartas diplomáticas propiamente dichas. Son documentos que no llevan ni fecha, ni firma, ni destinatario. Son memoriales descriptivos, aparentemente obtenidos y deliberadamente guardados con fin estrictamente informativo, para saber, desde la distancia de la península itálica en este caso (pero también desde otras latitudes, como demuestra el ejemplo francés), cuál había sido el desarrollo de los acontecimientos. Y que, según puede entreverse además a través de algunas referencias indirectas aparecidas en la documentación propiamente diplomática milanesa (como la carta a Francesco de abril de $1490 \ldots{ }^{83}$, fueron reproduciéndose y distribuyéndose, expandiéndose, a través de las redes diplomáticas. Era el propio entorno del monarca el que se preocupaba por generar y difundir estos informes quasi-cronísticos de los hechos más relevantes, cuyo detallado contenido iba mucho más allá de las habitualmente más escuetas notificaciones reales y propiamente diplomáticas sobre la obtención de plazas. Informes que iban circulando en cadena y que, a raíz de su circulación, se difundían y se podían ir traduciendo a discreción. De este modo, también se podían ir modelando y adaptando a los destinatarios, tanto en contenido como en forma y lenguaje. Pero no por ello dejaban de cumplir su función propagandística, que completaba la más estrictamente informativa que llegaba a través de la correspondencia diplomática epistolar.

Roma, por un lado, y Nápoles, por el otro, se nos representan claramente como polos o nodos fundamentales de esa difusión diferenciada de ambos tipos de información. Y si -aunque Génova pudiera quedar al margen de su circuito- desde Nápoles el eco propiamente diplomático reverberó, sobre todo,

82 Véase para ello, en concreto, María Dolores Rincón González, «La divulgación...», pp. 609 y siguientes.

83 Véase el texto correspondiente a la nota 64. 
hacia el centro y el norte de Italia, el «altavoz romano» ${ }^{84}$ ofreció la posibilidad de propulsarlo todavía más allá 85 .

\section{Epílogos: rituales escénicos y representación simbólica}

No hay duda de que, pese a la aparentemente limitada dimensión de sus festejos conmemorativos, el gran interés que Génova demostró por dejar patente ante los Reyes Católicos, ante su embajador y ante los mercaderes genoveses establecidos en Sevilla que celebró adecuadamente la caída de Granada tiene mucho de escénico y de voluntad (¿o de necesidad?) de demostrar su apoyo incondicional a los vencedores de la contienda. Procesión solemne, misa, fuegos y tañido de campanas también acompañaron las celebraciones en Florencia. Nápoles lo conmemoró, sin embargo, con procesiones solemnes, bailes y fiestas, iluminaciones y bombardas, $\mathrm{y}$ representaciones teatrales que se completaron, además, con «una specie di battaglia

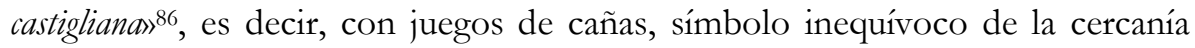
cultural o del intercambio y de los intensos contactos habidos durante décadas entre los súbditos peninsulares ibéricos y los campanos.

Las celebraciones podían graduarse, pues, tanto en función de la realidad de los lugares que lo celebraban como de la importancia de las plazas ganadas. En las tierras peninsulares de la Corona de Aragón, ante la notificación de cualquier victoria, se reaccionaba habitualmente con un Te Deum, varios días de procesiones, fuegos, iluminaciones, bombardas y tañido de campanas.

La pauta mínima para las celebraciones de 1492 nos la da Cervera: Te Deum, procesiones semejantes a la del Corpus durante varios días seguidos, paro de

84 En expresión de Álvaro Fernández de Córdova Miralles, «Imagen...», p. 307.

85 Ibidem, pp. 306-307, basándose fundamentalmente en María Dolores Rincón González, «La toma...» y «Presenza...», se refiere a los humanistas alemanes, pero señala también, por ejemplo, «ecos granadinos a través de las cartas de los procuradores romanos» en Borgoña (ibidem, p. 307). Advirtamos, sin embargo, la poca repercusión que, de acuerdo con el trabajo de Nikolas Jaspert publicado en este mismo volumen, tuvo la conquista de Granada en tierras imperiales.

86 Raúl González Arévalo, «La guerra...». 
talleres y obradores, tañido de campanas, supresión de lutos, música, bailes, justas y torneos ${ }^{87}$.

En el caso de Girona, donde conocemos con mucho más detalle el programa de los varios días de celebraciones ${ }^{88}$, podemos observar que el centro de gravitación de las mismas se fue moviendo de barrio, y que se implicaron, incluso, los judíos. Además, a la parte profana de la celebración -compuesta por juglares, músicos, cabalgatas y torneos- se puede sumar el detalle de los entremeses. Entremeses alusivos a la conquista de Granada que se preparan y llegan a escenificar, con sorprendente rapidez, en poquísimos días, porque si la noticia de la caída de Granada llegó a Girona el 17 de enero y las órdenes oficiales para celebrarla lo hicieron el 22, a partir del 29 ya se estuvo en condiciones de representar los entremeses. En primer lugar, un entremés o representación de la caída de Alhama, escenificando cómo los cristianos la tomaron de los moros, que la defendían por dentro y por fuera, y que llamó la atención por los espectaculares trajes y adornos de los participantes ${ }^{89}$. En segundo lugar, una representación en la que un legado apostólico coronaba emperadores a los Reyes Católicos. Y, por último, una escenificación de la conquista de Granada. Además, también sabemos que, tras la finalización de las procesiones, se ofreció un refrigerio, consistente en algún tipo de panificación de cereal, vino caliente, vino tinto, carnero, salchicha, azúcar, especias, naranjas y turrón ${ }^{90}$.

En Barcelona, tras la recepción de la notificación oficial, el mismo 18 de enero de 1492 la noticia de la caída se pregonó por la ciudad, se exhortó a todo el mundo a que acudiera a la catedral en acción de gracias, y se prohibió que se abrieran los obradores antes de mediodía. Se distribuyeron 4.000 linternas de

87 ACSG, Cervera, FM, Ordinacions, 1492, ff. 57r-58v. Cervera, 27 de enero de 1492.

88 Cf. Luis Batlle y Prats, «Fiestas...».

89 El valor simbólico de la toma de Alhama en el desarrollo de la guerra resulta evidente: un año después de su conquista, el rey Católico todavía hablaba de ello como de una hazaña reciente (véase Ernest Belenguer Cebrià, Col-lecció documental del regnat de Ferran II i la ciutat de València [1479-1516], Barcelona, Fundació Noguera, vol. I, doc. 58, p. 181).

90 Luis Batlle y Prats, «Fiestas...». 
papel por todo el perímetro de muralla, y frente al consistorio municipal y a la residencia del infante Juan. Se hicieron hogueras y se decidió hacer procesión, como la del Corpus, a celebrar el 24 de enero. El 19, hubo desfile del obispo y del clero catedralicio por toda la ciudad. El 21, se anunció solemnemente la procesión. El 22, el infante ofreció una recepción a los consellers y otros notables. Y los días 24, 25 y 26 los obradores se mantuvieron cerrados, y hubo más linternas, alimaras y hogueras, así como música, bailes, disfraces y juglares ${ }^{91}$. Pero no constan, sin embargo, entremeses ni representaciones teatrales. A destacar, también, en el caso de Barcelona, que un año después de la rendición de la capital nazarí, el 2 de enero de 1493, y estando el rey en la ciudad, el clero catedralicio hizo nueva procesión para conmemorarla ${ }^{92}$.

En Mallorca, Maria Barceló se sorprende del gran despliegue de medios dedicado a las celebraciones y de que, pese a la coyuntura de constante penuria económica, en ningún momento surjan problemas para dedicar dinero a las conmemoraciones $^{93}$. Caso particular lo constituye el de Zaragoza. Por un lado, por la insistencia en la presencia de reliquias, las de Santa Engracia, en las procesiones. Por otro lado, porque a los bailes y a las justas y torneos se les suman las corridas de toros. Pero también porque nos consta que la carta en que el rey Fernando comunicaba la victoria al cabildo catedralicio estuvo expuesta en la sacristía de la catedral, para que todos los zaragozanos pudieran contemplar la firma del monarca ${ }^{94}$.

Ni en la península ibérica ni en la Europa mediterránea más cercana, pues, el eco de la guerra fue uniforme. Porque no puede medirse, simplemente, por la proximidad o lejanía geográfica. Ni tampoco por la mayor o menor aportación de combatientes a la contienda ${ }^{95}$. Pero sí, desde luego, por el uso simbólico que

91 Manual de novells ardits..., vol. III, pp. 92-93.

92 Ibidem, p. 101.

93 Maria Barceló Crespí, «El eco...», p. 1385.

94 Domingo J. Buesa Conde, «Manifestaciones...», pp. 53-57.

95 Pese a la (relativamente) nutrida participación de combatientes procedentes de tierras imperiales (véase Eloy Benito Ruano, «Extranjeros en la Guerra de Granada», en Eloy Benito Ruano, Gente del siglo XV, Madrid, 1998, pp. 167-204 [reed. y puesta al día del trabajo publicado, bajo el mismo título, en Actas del I Congreso de Historia de Andalucia (diciembre de 
se hizo de la guerra o, fundamentalmente, de las relaciones con el Islam. Por ello, la Roma eminentemente preocupada por el verdadero eco del otro Islam mediterráneo (la amenaza y el avance turco-otomano) magnificó hasta tal punto la caída de Granada ${ }^{96} \ldots$

Porque, al fin y al cabo, hacía algo más de una década que las islas encantadas empezaban a ser visibles. Y que era patente, pues, que no quedaba mucho tiempo para que las campanas andaluzas pudieran volver a tocar al vuelo.

1976), Córdoba, 1978, vol. II, pp. 303-319], además de los trabajos señalados en la nota 3), según el trabajo de Nikolas Jaspert publicado en este mismo volumen, y como ya se ha indicado, allí el impacto de la conquista de Granada fue prácticamente nulo.

96 Véase en Fabrizio Cruciani, «Feste...», una síntesis de las representaciones teatrales preparadas. 